\title{
Labral Reattachment in Femoroacetabular Impingement Surgery Results in Increased 10-year Survivorship Compared With Resection
}

\author{
Helen Anwander MD, Klaus A. Siebenrock MD, Moritz Tannast MD, \\ Simon D. Steppacher MD
}

Published online: 15 October 2016

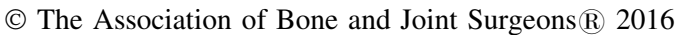

\begin{abstract}
Background Since the importance of an intact labrum for normal hip function has been shown, labral reattachment has become the standard method for open or arthroscopic treatment of hips with femoroacetabular impingement (FAI). However, no long-term clinical results exist evaluating the effect of labral reattachment. A 2-year followup comparing open surgical treatment of FAI with labral resection versus reattachment was previously performed at our clinic. The goal of this study was to report a concise followup of these patients at a minimum of 10 years.

Questions/purposes We asked if patients undergoing surgical hip dislocation for the treatment of mixed-type FAI with labral reattachment compared with labral resection had (1) improved hip pain and function based on the Merle d'Aubigné-Postel score; and (2) improved survival at 10 -year followup.
\end{abstract}

Two of the authors (HA, MT) have received funding from the Swiss National Science Foundation.

All ICMJE Conflict of Interest Forms for authors and Clinical

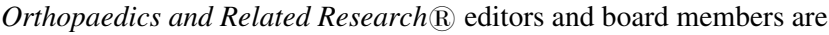
on file with the publication and can be viewed on request.

Clinical Orthopaedics and Related Research ${ }^{\mathbb{R}}$ neither advocates nor endorses the use of any treatment, drug, or device. Readers are encouraged to always seek additional information, including FDAapproval status, of any drug or device prior to clinical use. Each author certifies that his or her institution approved the human protocol for this investigation, that all investigations were conducted in conformity with ethical principles of research, and that informed consent for participation in the study was obtained.

H. Anwander, K. A. Siebenrock, M. Tannast,

S. D. Steppacher $(\bowtie)$

Department of Orthopaedic Surgery, Inselspital, Bern University

Hospital, University of Bern, CH-3010 Bern, Switzerland

e-mail: simon.steppacher@insel.ch
Methods Between June 1999 and July 2002, we performed surgical hip dislocation with femoral neck osteoplasty and acetabular rim trimming in 52 patients $(60$ hips) with mixed-type FAI. In the first 20 patients (25 hips) until June 2001, a torn labrum or a detached labrum in the area of acetabular rim resection was resected. In the next 32 patients (35 hips), reattachment of the labrum was performed. The same indications were used to perform both procedures during the periods in question. Of the 20 patients (25 hips) in the first group, 19 patients (95\%) (24 hips [96\%]) were available for clinical and/or radiographic followup at a minimum of 10 years (mean, 13 years; range, 12-14 years). Of the 32 patients (35 hips) in the second group, 29 patients (91\%) (32 hips [91\%]) were available for clinical and/or radiographic followup at a minimum of 10 years (mean, 12 years; range, $10-13$ years). We used the anterior impingement test to assess pain. Function was assessed using the Merle d'Aubigné- Postel score and ROM. Survivorship calculation was performed using the method of Kaplan-Meier with failure defined as conversion to THA, progression of osteoarthritis (of one grade or more on the Tönnis score), and a Merle d'Aubigné-Postel score $<15$.

Results At the 10-year followup, hip pain in hips with labral reattachment was slightly improved for the postoperative Merle d'Aubigné-Postel pain subscore $(5.0 \pm 1.0$ [3-6] versus $3.9 \pm 1.7[0-6] ; p=0.017)$. No difference existed for the prevalence of hip pain assessed using the anterior impingement test with the numbers available (resection group $52 \%$ [11 of $21 \mathrm{hips}$ ] versus reattachment group $27 \%$ [eight of 30 hips]; odds ratio, 3.03 ; 95\% confidence interval $[\mathrm{CI}], 0.93-9.83 ; \mathrm{p}=0.062$ ). Function was slightly better in the reattachment group for the overall Merle d'Aubigné-Postel score (16.7 \pm 1.5 [13-18] versus $15.3 \pm 2.4[9-18] ; \mathrm{p}=0.028)$ and hip abduction $\left(45^{\circ} \pm\right.$ 
$13^{\circ}$ [range, $30^{\circ}-70^{\circ}$ ] versus $38^{\circ} \pm 8^{\circ}$ [range, $25^{\circ}-45^{\circ}$ ]; $\mathrm{p}=$ 0.001). Hips with labral reattachment showed a better survival rate at 10 years than did hips that underwent labral resection $(78 \%$; 95\% CI, 64\%-92\% versus $46 \%, 95 \% \mathrm{CI}$, $26 \%-66 \% ; \mathrm{p}=0.009)$ with the endpoints defined as conversion to THA, progression of osteoarthritis, and a Merle d'Aubigné-Postel score $<15$. With isolated endpoints, survival at 10 years was increased for labral reattachment and the endpoint Merle d'Aubigné score < $15(83 \%, 95 \%$ CI, 70\%-97\% versus $48 \%, 95 \%$ CI, 28\%-69\%; $\mathrm{p}=0.009$ ) but did not differ for progression of osteoarthritis $(83 \%$, $95 \% \mathrm{CI}, 68 \%-97 \%$ versus $81 \%, 95 \% \mathrm{CI}, 63 \%-98 \%$; $\mathrm{p}=$ $0.957)$ or conversion to THA $(94 \%, 95 \%$ CI, $86 \%-100 \%$ versus $87 \%, 95 \% \mathrm{CI}, 74 \%-100 \%$; $\mathrm{p}=0.366)$.

Conclusions The current results suggest the importance of preserving the labrum and show that resection may put the hip at risk for early deterioration. At 10-year followup, hips with labral reattachment less frequently had a decreased Merle d'Aubigné score but no effect on progression of osteoarthritis or conversion to THA could be shown.

Level of Evidence Level III, therapeutic study.

\section{Introduction}

The importance of an intact labrum for normal hip function has been shown in cadaveric $[10,25,30]$ and computersimulated studies [9]. The main function is to seal the joint and create a hydrostatic synovial fluid film between the cartilage layers. This fluid film prevents direct cartilage-oncartilage contact and results in a more homogenous load distribution in the joint [10]. Labral tears or partial resection negatively affect the sealing function resulting in impaired intraarticular fluid pressurization putting the joint at risk for deterioration [9, 30]. Labral reattachment or reconstruction has the potential to improve hip function to levels similar to the intact state of the labrum [10, 30]. However, in earlier surgical treatments of hips with femoroacetabular impingement (FAI), the labrum was often resected after acetabular rim trimming or in areas with labral damage.

Preservation of the labrum has increasingly been performed consistent with the growing evidence of the importance of the labrum. Reattachment or reconstruction of the labrum in hips after open or arthroscopic surgery for FAI has become the standard treatment. However, there is only limited clinical evidence about the beneficial effect of labral reattachment compared with resection. At short-term followup, improved hip pain was found in hips after arthroscopic surgical treatment of the labrum [5, 15-17, 29, 33]. At a 2-year followup, Espinosa et al. [8] could show improved hip pain and decreased radiographic signs of osteoarthritis in hips after surgical hip dislocation for hip-preserving surgery (acetabular rim trimming and femoral osteochondroplasty) with labral reattachment compared with labral resection. To date, no long-term clinical results exist evaluating the effect of labral reattachment.

The goal of this study was to report a concise followup at a minimum 10 years of a previously published patient series from our institution [8] comparing labral reattachment with labral resection in hips after open surgical treatment for FAI. We asked if patients undergoing surgical hip dislocation and surgical treatment of mixed-type FAI with labral reattachment compared with labral resection had (1) improved hip pain and function as measured by an anterior impingement test, ROM, and Merle d'AubignéPostel score; and (2) a superior survival rate at 10-year followup with the endpoints defined as conversion to THA, progression of osteoarthritis of one grade or more on the Tönnis score, and a Merle d'Aubigné-Postel score $<15$.

\section{Patients and Methods}

We retrospectively reviewed the same subset of 52 patients (60 hips) who had undergone surgical hip dislocation and treatment of FAI comparing labral reattachment and resection with a 2-year followup [8] performed at our institution. The indication for surgical hip dislocation with femoral neck osteoplasty and acetabular rim trimming was symptomatic hips with mixed-type FAI. For the total of 149 procedures (141 patients) performed during this period of time, our exclusion criteria [8] eliminated hips with incomplete clinical or radiological documentation (48 hips in 48 patients), hips with an open growth plate (four hips in four patients), age at surgery of older than 40 years (29 hips in 29 patients), previous hip surgery (seven hips in seven patients), and one patient (one hip) participating in professional athletic activity. This resulted in a total of 52 patients (60 hips) for evaluation (Table 1). The procedures were performed between June 1999 and July 2002. In the first 20 patients (25 hips) until June 2001, a torn labrum or the detached labrum in the area of acetabular rim resection was resected (resection group). In the following 32 patients (35 hips), reattachment to the acetabular rim was performed for a torn labrum or a labrum detached from the rim (reattachment group). The same indications were used to perform both procedures during the periods in question; this was a sequential series with the labral resections being performed in the earlier part of the study period and the labral reattachments being performed in the latter portion of the study period. 
Table 1. Demographic parameters of the two study groups

\begin{tabular}{llll}
\hline Parameters & Labral resection & Labral reattachment & $\mathrm{p}$ value \\
\hline Number of patients (hips) & $20(25)$ & $32(35)$ & $29 \pm 6(20-38)$ \\
Age (years) & $29 \pm 7(17-40)$ & 63 & 0.726 \\
Sex (percentage male of all hips)* & 76 & 49 & 0.784 \\
Side (percentage right of all hips) & & $174 \pm 9(157-195)$ & 0.067 \\
Height $(\mathrm{cm})$ & 72 & $73 \pm 13(45-103)$ & 0.298 \\
Weight $(\mathrm{kg})$ & $77 \pm 15(55-111)$ & $24 \pm 4(19-32)$ & 0.326 \\
Body mass index $\left(\mathrm{kg} / \mathrm{m}^{2}\right)$ & $25 \pm 4(19-37)$ & 100 & 0.780 \\
Type of FAI (percentage mixed-type) & 100 & 0.870 \\
\hline
\end{tabular}

Values of continuous parameters are expressed as mean \pm SD with range in parentheses; * odds ratio of 1.26 (95\% confidence interval [CI], $0.42-3.71) ;{ }^{\dagger}$ odds ratio of 2.72 (95\% CI, 0.91-8.15); ${ }^{*}$ odds ratio of 0.72 (95\% CI, 0.01-37.4); FAI = femoroacetabular impingement.

Of the 20 patients ( 25 hips) in the first group, 19 patients (95\%) (24 hips [96\%]) were available for clinical and/or radiographic followup at a minimum of 10 years (mean, 13 years; range, $12-14$ years). Of the 32 patients (35 hips) in the second group, 29 patients (91\%) (32 hips [91\%]) were available for clinical and/or radiographic followup at a minimum of 10 years (mean, 12 years; range, 10-13 years). Four patients (four hips) were not available for a minimum 10-year clinical and radiographic followup. One patient (one hip) in the resection group was lost to followup 2 years after surgery without progression of osteoarthritis or conversion to THA. He presented with a good clinical result (Merle d'Aubigné-Postel score of 18) at his last followup. Three patients (three hips) in the reattachment group were lost to followup between 2 and 6 years after surgery without progression of osteoarthritis or conversion to THA. They presented with a good clinical result (Merle d'Aubigné-Postel score ranging from 17 to 18) at their last followup. This resulted in a total of 48 patients (56 hips) for evaluation at a minimum 10-year followup.

The mean followup in the resection group was 13 years (range, 12-14 years) and 12 years (range, 10-13 years) in the reattachment group. We had complete clinical and radiographic followup in 42 patients (48 hips). The other six patients (eight hips) had a good clinical followup at a minimum of 10 years (Merle d'Aubigné-Postel score exceeding 15 points) and refused radiographic evaluation at 10-year followup. Those patients had radiographic evaluation between 2 and 6 years after surgery without progression of osteoarthritis. Therefore, these six patients (eight hips) were included in the survival analysis as survivors. The mean radiographic followup of the total of 52 patients (60 hips) with the last radiograph available was 9 years (range, 2-14 years).

The study was approved by the local institutional review board.

For the clinical and radiographic evaluation of the patients, the same assessment scheme from the previous report [8] was used. Clinical evaluation included the patient's history, anterior impingement test (pain in combined flexion and internal rotation, for this study defined as present or absent), and assessment of the full range of hip motion. As a clinical scoring system, the Merle d'AubignéPostel score [7] was assessed preoperatively and at 10-year followup. Different observers performed the clinical evaluation preoperatively and at the most recent followup. At followup, clinical evaluation was performed by one of us not involved in the surgical care of the patients (HA). Substantial inter- and intraobserver agreement has been reported for ROM [12, 20, 40], the anterior impingement test [19], and the Merle d'Aubigné-Postel score [7]. Radiographic evaluation consisted of an AP pelvic radiograph and a cross-table lateral view of the hip acquired in a standardized fashion [37] pre- and postoperatively. The radiographic morphology of the acetabulum and the proximal femur was evaluated using a validated and computerized method, which also allowed calculation of acetabular coverage (Table 2). Osteoarthritis was graded according to the classification of Tönnis [38]. These radiographic parameters were evaluated by one of us not involved in the surgical care of the patients (HA).

A detailed description of surgical hip dislocation has been previously published [11]. In short, the patient was positioned in the lateral decubitus position, the interval between the gluteus maximums and medius muscle (Gibson interval) was developed, and trochanteric osteotomy was performed. The anterior capsule was opened through a Z-shaped capsulotomy in the interval between the piriformis and the gluteus minimus muscle. The hip was subluxated, the ligamentum teres cut, the hip then completely luxated, and the ligamentum teres excised. With the femoral head and the acetabulum exposed, the labrum and the cartilage were inspected and graded according to Beck et al. [2]. A hemispheric plastic template was used to define the aspherical portion at the femoral head-neck junction, which subsequently was corrected. On the acetabular side, the labrum was surgically detached and the excessive part of the acetabular rim resected. In the first 20 patients, the 
Table 2. Pre- and postoperative radiographic parameters of the two study groups (resection group including 25 hips in 20 patients and reattachment group including 35 hips in 32 patients)

\begin{tabular}{|c|c|c|c|c|c|c|}
\hline \multirow[t]{2}{*}{ Parameter } & \multicolumn{3}{|l|}{ Preoperative } & \multicolumn{3}{|l|}{ Postoperative } \\
\hline & Resection group & $\begin{array}{l}\text { Reattachment } \\
\text { group }\end{array}$ & $\begin{array}{l}\mathrm{p} \\
\text { value }\end{array}$ & Resection group & $\begin{array}{l}\text { Reattachment } \\
\text { group }\end{array}$ & $\begin{array}{l}\mathrm{p} \\
\text { value }\end{array}$ \\
\hline Lateral center-edge angle [39] (degrees) & $33 \pm 11(12-54)$ & $32 \pm 9(17-46)$ & 0.768 & $30 \pm 8(11-41)$ & $29 \pm 8(10-42)$ & 0.619 \\
\hline Acetabular index [38] (degrees) & $6 \pm 7(-2$ to 17$)$ & $4 \pm 6(-9$ to 17$)$ & 0.373 & $\begin{array}{l}1 \pm 5(-8 \text { to } \\
10)\end{array}$ & $2 \pm 5(-9$ to 16$)$ & 0.533 \\
\hline Extrusion index [22] (percent) & $22 \pm 11(3-9)$ & $20 \pm 8(6-35)$ & 0.589 & $21 \pm 8(6-40)$ & $22 \pm 8(6-40)$ & 0.547 \\
\hline Crossover sign [32] (percent positive) & $40 *$ & $49^{*}$ & 0.624 & $24^{\dagger}$ & $14^{\dagger}$ & 0.266 \\
\hline Caudocranial femoral coverage (percent) & $\begin{array}{l}77 \pm 13(52- \\
100)\end{array}$ & $79 \pm 9(64-92)$ & 0.527 & $77 \pm 9(53-90)$ & $75 \pm 9(56-92)$ & 0.624 \\
\hline Anterior coverage (percent) & $23 \pm 8(9-31)$ & $25 \pm 7(16-42)$ & 0.493 & $23 \pm 6(10-32)$ & $18 \pm 7(30-56)$ & 0.029 \\
\hline Posterior coverage (percent) & $38 \pm 15(15-68)$ & $41 \pm 7(32-57)$ & 0.565 & $39 \pm 8(20-52)$ & $42 \pm 7(31-56)$ & 0.234 \\
\hline Alpha angle in axial view [26] (degrees) & $67 \pm 9(51-76)$ & $70 \pm 6(59-82)$ & 0.425 & $42 \pm 6(30-50)$ & $43 \pm 5(33-51)$ & 0.367 \\
\hline $\begin{array}{l}\text { Osteoarthritis according to Tönnis classification } \\
\text { [38] }\end{array}$ & & & & - & & - \\
\hline Grade 0 (percent) & $10(40)$ & $18(51)$ & 0.382 & & & \\
\hline Grade 1 (percent) & $15(60)$ & $16(46)$ & 0.275 & & & \\
\hline Grade 2 (percent) & 0 & $1(3)$ & 0.394 & & & \\
\hline Grade 3 (percent) & 0 & 0 & - & & & \\
\hline
\end{tabular}

Values of continuous parameters are expressed as mean \pm SD with range in parentheses; * odds ratio of 0.71 (95\% confidence interval $[\mathrm{CI}]$, $0.25-2.00$ ); ${ }^{\dagger}$ odds ratio of 1.89 (95\% CI, 0.51-7.08).

torn labrum or the detached labrum in the area of acetabular rim resection was resected. In the following 32 patients, the torn labrum or the detached labrum in the area of acetabular rim resection was reattached using two to six titanium bone anchors with nonabsorbable sutures (G II Titanium Anchor; DePuy, Mitek, Norwood, MA, USA) being passed through the base of the labrum and knots being placed on the outer surface. Only the ossified portion of degenerated labrum was resected. After verification of impingement-free ROM, the capsule and the wound were closed in layers and the greater trochanter was reattached using two to three $3.5-\mathrm{mm}$ cortical screws.

The two study groups did not differ in 32 of 35 parameters describing demography (Table 1), the preoperative and postoperative radiographic morphology of the hip (Table 2), and the preoperative clinical status or the extent of intraoperative assessed cartilage and labral damage (Table 3). The two study groups differed in terms of preoperative flexion (Table 3), acetabular cartilage damage (Table 3), and postoperative anterior acetabular coverage (Table 2). In hips with labral resection, the preoperative flexion was decreased with a mean of $93^{\circ} \pm 12^{\circ}$ $\left(\right.$ range, $\left.70^{\circ}-110^{\circ}\right)$ versus $106^{\circ} \pm 12^{\circ}\left(\right.$ range, $\left.70^{\circ}-110^{\circ}\right)$ in hips with labral reattachment $(\mathrm{p}<0.001$; Table 3$)$. The percentage of cleavage lesions of the acetabular cartilage was increased in hips with labral resection compared with hips with reattachment $(52 \%$ versus $24 \%$; Table $3 ; p=$ 0.037 ) with a correspondingly decreased percentage of debonding lesions in hips with labral resection (Table 3). Postoperatively, the anterior acetabular coverage was increased in hips with labral resection with a mean coverage of $23 \%$ versus $19 \%$ in hips with labral reattachment (Table 2; $\mathrm{p}=0.029$ ).

At the 10-year followup, hip pain was compared using the prevalence of a positive anterior impingement test and the pain subscore of the Merle d'Aubigné-Postel score. Hip function was compared using the Merle d'Aubigné-Postel score and the full ROM. Survival rate at the 10-year followup was calculated with any of the following endpoints: conversion to THA, progression of osteoarthritis by at least one grade according to Tönnis, or a Merle d'AubignéPostel score of $<15$ at most recent followup.

Normal distribution was tested using the KolmogorovSmirnov test. We compared demographic, clinical, radiographic, and surgery-related parameters between the two study groups using the independent Student's t-test for continuous data and the chi square test for binominal data. Survival rate was calculated according to the method of Kaplan-Meier [14] with the previously defined endpoints. Difference in survival at 10-year followup between the two study groups was tested using the log-rank test.

\section{Results}

At the 10-year followup, hip pain in hips with labral reattachment was slightly improved for the Merle d'Aubigné- 
Table 3. Preoperative clinical parameters and intraoperative cartilage and labrum damage of the two study groups

\begin{tabular}{|c|c|c|c|}
\hline Parameter (best-worst score possible) & Labral resection & Labral reattachment & $\mathrm{p}$ value \\
\hline Number of patients (hips) & $20(25)$ & $32(35)$ & - \\
\hline Merle d'Aubigné-Postel score [7] (18-0) & $12.4 \pm 1.9(8-14)$ & $12.6 \pm 1.8(5-16)$ & 0.659 \\
\hline Pain $(6-0)$ & $1.4 \pm 0.8(0-2)$ & $1.5 \pm 0.9(0-4)$ & 0.682 \\
\hline Mobility (6-0) & $5.4 \pm 0.8(4-6)$ & $5.6 \pm 0.6(4-6)$ & 0.136 \\
\hline Walking ability (6-0) & $5.6 \pm 0.7(4-6)$ & $5.5 \pm 1.1(1-6)$ & 0.611 \\
\hline \multicolumn{4}{|l|}{ ROM } \\
\hline Flexion (degrees) & $93 \pm 12(70-110)$ & $106 \pm 12(70-110)$ & $<0.001$ \\
\hline Internal rotation (degrees)* & $8 \pm 18(0-30)$ & $15 \pm 11(0-30)$ & 0.283 \\
\hline Anterior impingement test (percent positive) ${ }^{\dagger}$ & 88 & 86 & 0.557 \\
\hline \multicolumn{4}{|c|}{ Femoral cartilage damage classified according to Beck et al. [2] } \\
\hline Normal (percentage) & $13(52)$ & $24(68)$ & 0.193 \\
\hline Malacia (percentage) & $11(44)$ & $11(32)$ & 0.320 \\
\hline Debonding (percentage) & $1(4)$ & 0 & 0.233 \\
\hline Cleavage (percentage) & 0 & 0 & - \\
\hline Defect (percentage) & 0 & 0 & - \\
\hline \multicolumn{4}{|c|}{ Acetabular cartilage damage classified according to Beck et al. [2] } \\
\hline Normal (percentage) & $1(4)$ & 0 & 0.233 \\
\hline Malacia (percentage) & $4(16)$ & $9(26)$ & 0.368 \\
\hline Debonding (percentage) & $2(8)$ & $13(38)$ & 0.010 \\
\hline Cleavage (percentage) & $13(52)$ & $9(26)$ & 0.037 \\
\hline Defect (percentage) & $5(20)$ & $4(12)$ & 0.359 \\
\hline \multicolumn{4}{|c|}{ Labral damage classified according to Beck et al. [2] } \\
\hline Normal (percentage) & 0 & $2(6)$ & 0.224 \\
\hline Degeneration (percentage) & $6(24)$ & $9(26)$ & 0.880 \\
\hline Full-thickness tear (percentage) & $9(36)$ & $15(41)$ & 0.593 \\
\hline Detachment (percentage) & $1(4)$ & $2(6)$ & 0.764 \\
\hline Ossification (percentage) & $9(36)$ & $7(21)$ & 0.167 \\
\hline Operation time (hours) & $2.4 \pm 0.6(1.5-4.5)$ & $2.5 \pm 0.5(1.5-4.0)$ & 0.561 \\
\hline
\end{tabular}

Values of continuous parameters are expressed as mean \pm SD with range in parentheses; * internal rotation was analyzed with $90^{\circ}$ flexion in the hip and knee; ${ }^{\dagger}$ odds ratio was 1.22 (95\% confidence interval, 0.26-5.66).

Postel pain subscore $(5.0 \pm 1.0[3-6]$ versus $3.9 \pm 1.7[0$ 6]; $\mathrm{p}=0.017$; Table 4). No difference existed for the prevalence of a positive anterior impingement test (resection group with 11 of 21 hips [52\%] versus reattachment group with eight of 30 hips [27\%], odds ratio, 3.03; 95\% confidence interval [CI], 0.93-9.83; $\mathrm{p}=0.062$; Table 4). Hip function in hips with labral reattachment was slightly increased for the overall Merle d'Aubigné-Postel score (16.7 \pm 1.5 [13-18] versus $15.3 \pm 2.4[9-18] ; \mathrm{p}=0.028)$ and hip abduction $\left(45^{\circ} \pm 13^{\circ}\left[30^{\circ}-70^{\circ}\right]\right.$ versus $38^{\circ} \pm 8^{\circ}\left[25^{\circ}-45^{\circ}\right] ; p=0.001$; Table 4). No difference existed for flexion, extension, internal rotation, external rotation, or adduction between hips with labral reattachment and resection ( $\mathrm{p}$ ranging from 0.082 to 1.000 ; Table 4$)$.

Hips with labral reattachment showed a better survival rate at 10 years (endpoints defined as conversion to THA, radiographic progression of osteoarthritis, or a Merle
d'Aubginé score of $<15)$ than did hips that underwent labral resection $(78 \%, 95 \%$ CI, $64 \%-92 \%$ versus $46 \%$, 95\% CI, 26\%-66\%; $p=0.009$ ) (Fig. 1). In the group with labral reattachment, seven hips $(20 \%)$ reached an endpoint including conversion to THA in two hips (6\%), progression of osteoarthritis in five hips (14\%), and a Merle d'AubignéPostel score of $<15$ in five hips (14\%). In the group with labral resection, 13 hips (52\%) reached an endpoint including conversion to THA in three hips (12\%), progression of osteoarthritis in four hips (16\%), and a Merle d'Aubigné-Postel score of $<15$ in 12 hips (48\%). Survival at 10 years with single endpoints was as follows: for a Merle d'Aubigné score of $<15$, mean survival was increased with labral reattachment $(83 \%$; 95\% CI, 70\%$97 \%$ ) compared with labral resection (48\%; 95\% CI, $28 \%$ $69 \% ; \mathrm{p}=0.009)$. No difference in survival with the endpoint as conversion to THA only was found between hips 
Table 4. Clinical results at followup (including only hips with a minimum 10-year followup)

\begin{tabular}{|c|c|c|c|}
\hline Parameters (best-worst score possible) & Resection group & Reattachment group & $\mathrm{p}$ value \\
\hline Number of patients (hips) & $17(21)$ & $28(30)$ & - \\
\hline Merle d'Aubigné-Postel score [7] (18-0) & $15.3 \pm 2.4(9-18)$ & $16.7 \pm 1.5(13-18)$ & 0.028 \\
\hline Pain $(6-0)$ & $3.9 \pm 1.7(0-6)$ & $5.0 \pm 1.0(3-6)$ & 0.014 \\
\hline Mobility (6-0) & $5.7 \pm 0.7(4-6)$ & $5.8 \pm 0.4(5-6)$ & 0.473 \\
\hline Walking Ability (6-0) & $5.8 \pm 0.4(5-6)$ & $5.9 \pm 0.3(5-6)$ & 0.228 \\
\hline \multicolumn{4}{|l|}{ ROM } \\
\hline Flexion (degrees) & $99 \pm 14(70-120)$ & $102 \pm 11(90-130)$ & 0.388 \\
\hline Extension (degrees) & $5 \pm 3(0-10)$ & $5 \pm 3(0-10)$ & 1.000 \\
\hline External rotation (degrees) & $39 \pm 26(5-80)$ & $36 \pm 15(10-75)$ & 0.542 \\
\hline Internal rotation (degrees) & $21 \pm 13(0-45)$ & $20 \pm 13(0-45)$ & 0.640 \\
\hline Abduction (degrees) & $38 \pm 8(25-45)$ & $45 \pm 13(30-70)$ & 0.048 \\
\hline Adduction (degrees) & $20 \pm 8(59-40)$ & $22 \pm 6(15-30)$ & 0.082 \\
\hline Anterior impingement test (percent positive)* & 52 & 27 & 0.062 \\
\hline
\end{tabular}

Values are mean \pm SD with range in parentheses; *odds ratio of 3.03 with $95 \%$ confidence interval of $0.93-9.83$

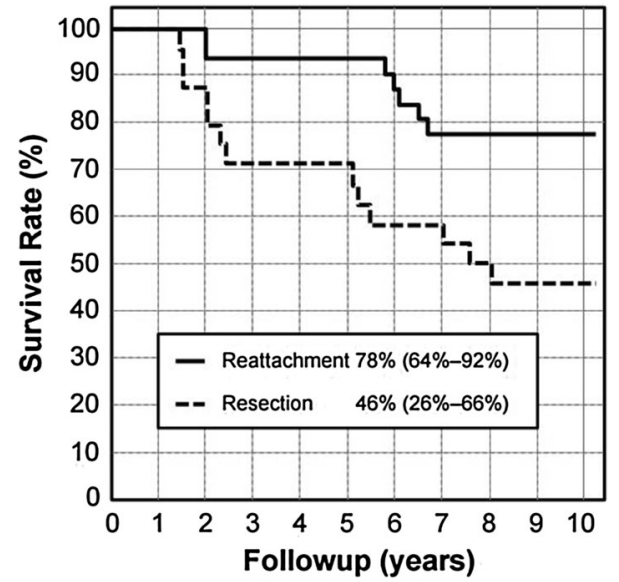

Fig. 1 Hips with labral reattachment (continuous line) showed an increased mean survival rate at 10 years of $78 \%$ (95\% CI, 64\%-92\%) compared with hips with labral resection (broken line; mean survival rate of $46 \%$ [95\% CI, 26\%-66\%; $\mathrm{p}=0.009]$ )

with labral reattachment (94\%; 95\% CI, 86\%-100\%) and resection $(87 \%$; 95\% CI, 74\%-100\%; $\mathrm{p}=0.366)$ and for the endpoint as progression of osteoarthritis only between hips with labral reattachment $(83 \%$; 95\% CI, 68\%-97\%) and resection (81\%; 95\% CI, 63\%-98\%; $\mathrm{p}=0.957)$.

\section{Discussion}

The importance of an intact labrum for normal hip function has been shown in cadaveric $[10,25,30]$ and computersimulated studies [9]. A beneficial effect on joint preservation and hip pain has been suggested at short-term clinical followup [8, 15, 16, 29, 33]. The aim of the current study was to evaluate hip pain, function, and survival of the joint at 10-year followup for labral reattachment in open surgical treatment of hips with FAI and compare with those hips with labral resection. Pain was slightly improved for hips with labral reattachment using the Merle d'AubignéPostel pain subscore but no difference was found for the prevalence of the anterior impingement test. Function was improved in hips with labral reattachment for the overall Merle d'Aubigné-Postel score and abduction, but this difference was clinically small ( $7^{\circ}$ of abduction) and perhaps not important. Survival of hips treated with labral reattachment, with endpoints defined as conversion to THA, progression of osteoarthritis, or a poor clinical result (Merle d'Aubigné-Postel score $<15$ ), was $78 \%$; this was better than what we observed in hips after labral resection $(46 \% ; p=0.009)$.

The study has several limitations. The main limitation is that the two study groups were not entirely comparable regarding the preoperative demographics (Table 1), radiographic parameters and surgical correction (Table 2), or clinical parameters and intraoperatively assessed cartilage/ labral damage (Table 3). Three of 35 parameters were different including preoperative flexion, intraoperatively assessed cartilage damage, and postoperative anterior acetabular coverage. The increased prevalence of cleavage lesions of the acetabular cartilage in hips with labral resection (Table 3 ) could have decreased the survival rate in these hips. In addition, the decreased preoperative flexion in hips with labral resection (Table 3) could be the result of a more severe form of FAI; however, the radiographic morphology of the acetabulum and the proximal femur did not differ between the study groups (Table 2). These two factors potentially could have decreased 
survival in hips with labral resection; however, neither factor is a known negative predictive factor $[34,35]$ and a difference of $32 \%$ in survival at 10 -year followup is very unlikely the exclusive result of these differences. The third parameter differing between the two study groups was the postoperative anterior acetabular coverage with a mean of $23 \%$ in hips with labral resection and $18 \%$ in hips with reattachment (Table 3 ). These values are both within the normal range of $19 \% \pm 6 \%$ (range, $7 \%-29 \%$ ) for anterior acetabular coverage [36] and should therefore not have influenced the results to a significant extent. An additional limitation is that the numbers of exclusion are relatively high with 89 hips $(60 \%)$ excluded mainly as a result of incomplete documentation or an age exceeding 40 years at operation. The goal of the current study was to report an update of the original series previously published [8]. The high number excluded could have influenced our results and makes our findings only valid for patients younger than 40 years. However, most patients eligible for FAI surgery are younger than 40 years (up to $84 \%$ in long-term studies $[34,35])$ because an age at operation exceeding 40 years is a known negative predictive factor [34]. Third, the numbers of patients and hips in both study groups were limited ( 25 and 35 hips in the resection and reattachment groups, respectively), which might have negatively affected power for calculating differences between the two study groups, eg, a prevalence of a positive anterior impingement test at followup of $52 \%$ in the resection group and $27 \%$ in the reattachment group (Table 4) was not significantly different (although with $\mathrm{p}=0.062$, there was a clear tendency).

There are additional limitations that need to be considered. The Merle d'Aubigné-Postel score is a relatively crude score for patients with FAI. Although we found an increased score in hips with labral reattachment at 10-year
Fig. 2A-F (A) A 27-year-old male patient presented with mixed-type FAI, a Merle d'Aubigné-Postel score of 14 , and radiologic osteoarthritis Grade 1 according to Tönnis. (B) The preoperative alpha angle was $63^{\circ}$. (C) He underwent surgical hip dislocation with acetabular rim trimming, reattachment of the labrum using four titanium bone anchors, and (D) osteochondroplasty of the neck. (E) At 11 years followup, the patient did not show progression of osteoarthritis $(\mathbf{F})$ and had an excellent clinical result (Merle d'Aubigné-Postel score of 18).
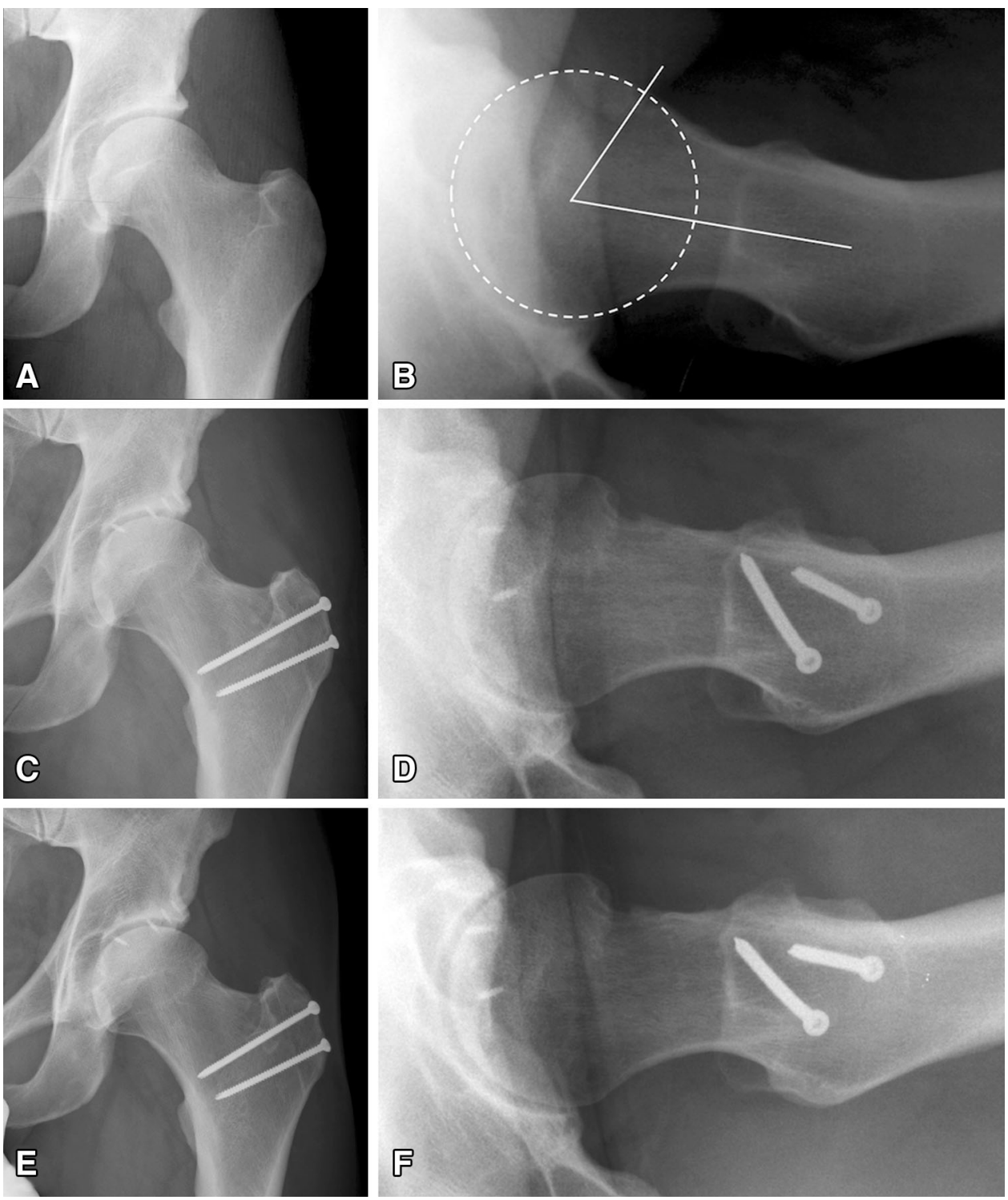
Fig. 3A-F (A) A 33-year-old male patient presented with mixed-type FAI, a Merle d'Aubigné-Postel score of 13 , and radiologic osteoarthritis Grade 1 according to Tönnis. (B) The preoperative alpha angle was $60^{\circ}$. (C) He underwent surgical hip dislocation with trimming of the excessive part of the acetabular rim, resection of the labrum in the area of rim resection, and (D) osteochondroplasty of the neck. (E) At 5 years followup, the patient did show progression of osteoarthritis, increased pain, and impaired mobility and, therefore, $(\mathbf{F})$ the hip had to be converted to THA at 5.5-year followup.
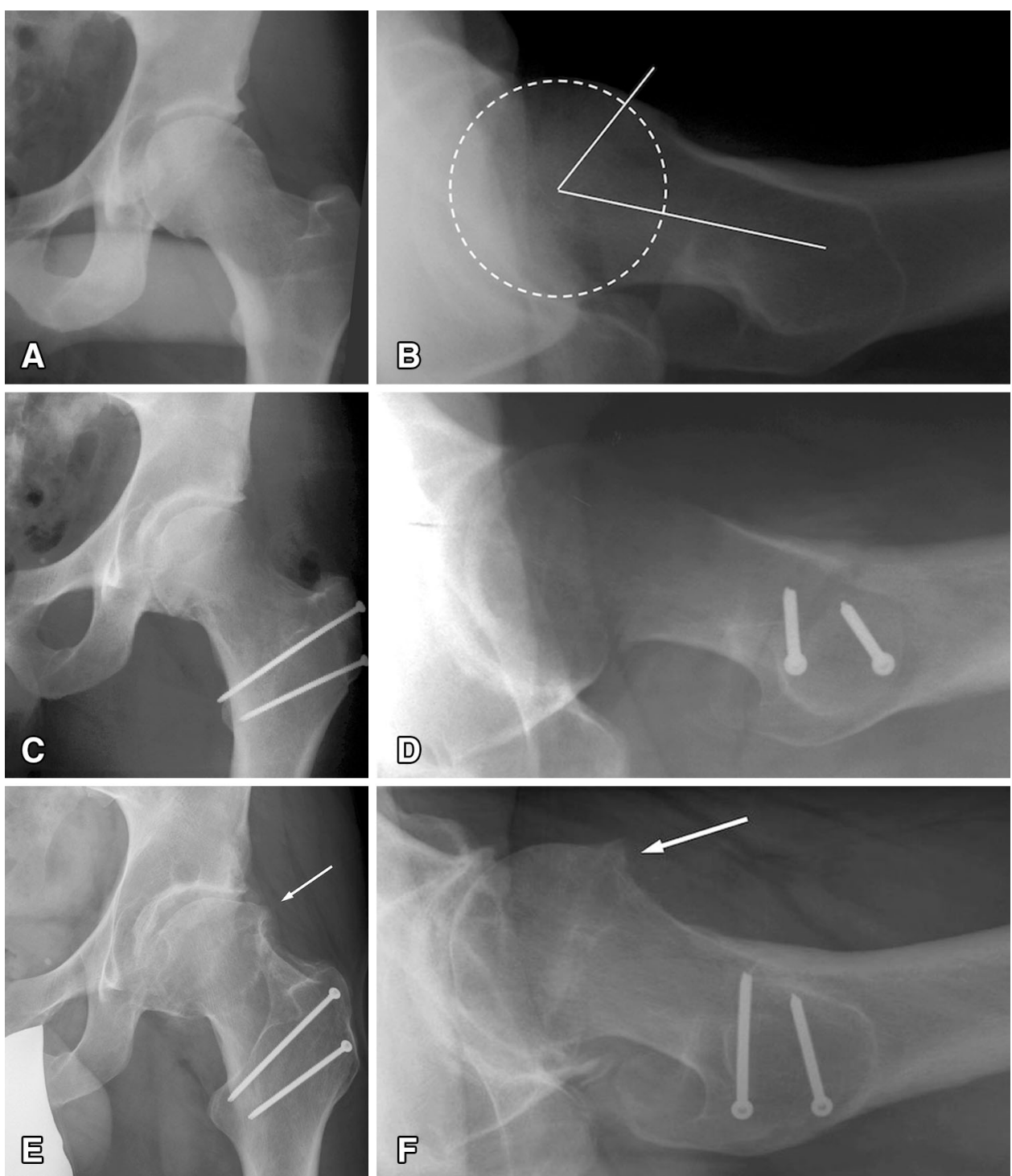

Fig. 4 Bubble chart showing followup, survival rate (with THA as the endpoint), size of the patient series (size of bubble), and the color-coded treatment of the labrum. Studies with $100 \%$ of labral reattachment are represented in black, labral resection in white, and percentage of labral reattachment in corresponding gray scales

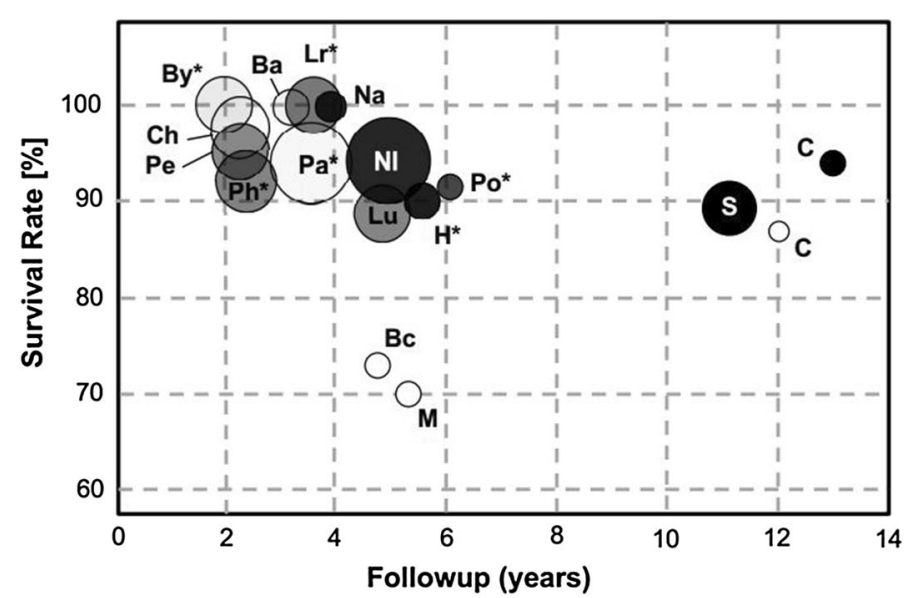

Bc Beck et al, 2004 [3]

M Murphy et al, 2004 [21]

Ba Beaulé et al, 2007 [1]

Lr* Larson et al, 2012 [16]

Lu Laude et al, 2009 [17]

Pe Peters et al, 2010 [26]

$\mathrm{Ph}^{\star}$ Philippon et al, 2009 [27]

By* Byrd et al, 2011 [4]

$\mathrm{Na}$ Naal et al, 2011[23]

Ch Chiron et al, 2012 [6]

NI Naal et al, 2012 [22]

Pa* Palmer et al, 2012 [25]

Po* Polesello et al, 2014 [29]

$\mathbf{H}^{\star} \quad$ Hufeland et al, 2016 [13]

S Steppacher et al, 2014 [32]

C Current Study

* arthroscopic surgery 


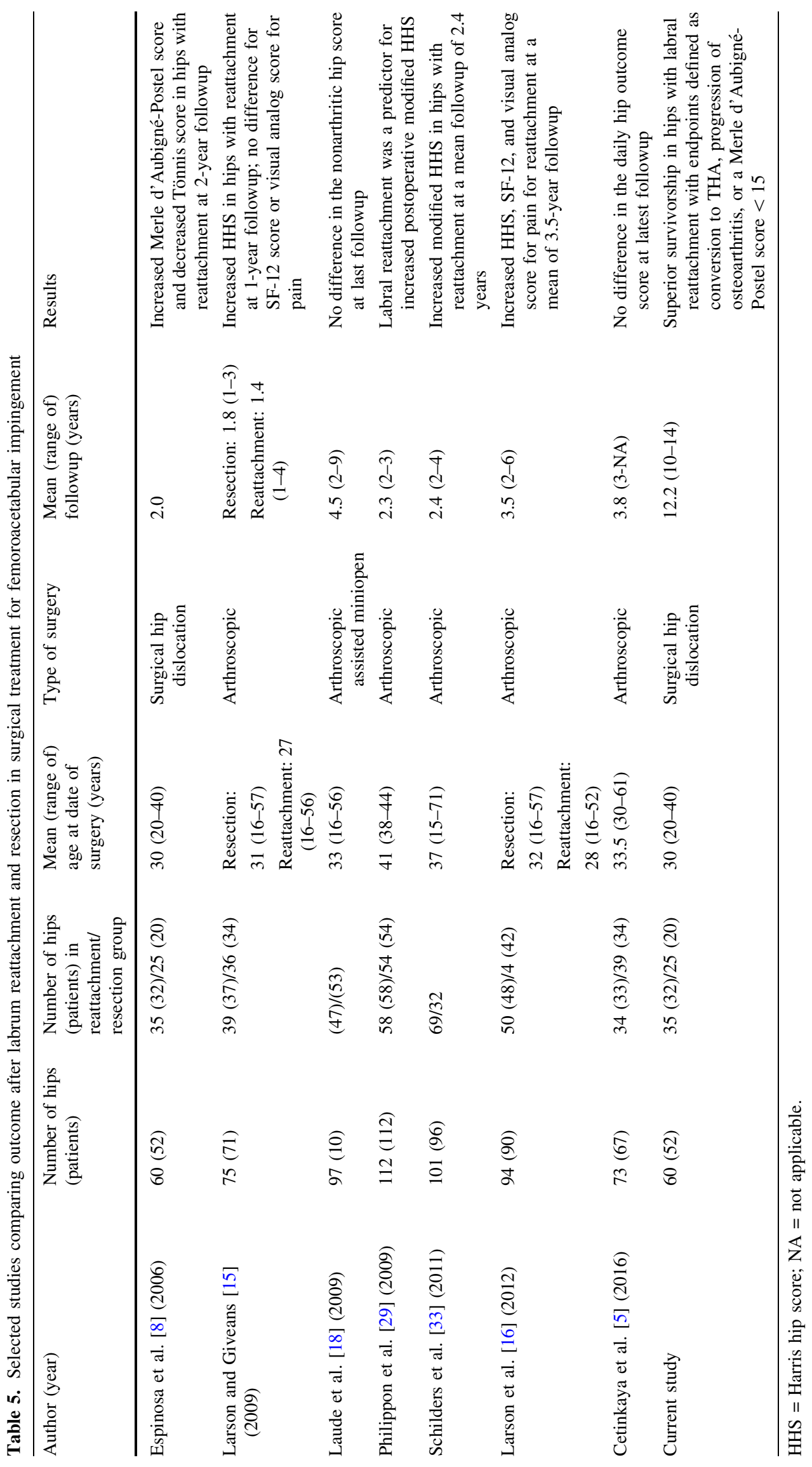


followup, the difference we observed was small, and may not be clinically important. Next, the impingement test only has fair agreement (intraclass correlation coefficient of 0.58 [range, 0.29-0.97; percent agreement of 91\% [19]), which might have influenced our results because different observers recorded the impingement test preoperatively and at followup. In addition, the observer evaluating radiographs at followup (HA; one of us not involved in the surgical care of the patients) could not be blinded as a result of the use of metallic anchors for reattachment of the labrum that were clearly visible on the radiographs. An additional limitation is that not all patients could be followed up for at least 10 years with four patients (four hips) not available for minimum 10-year clinical and radiographic followup. These censored data could have affected the results for hip pain and function. It did not influence survivorship calculation because the statistical tests applied (Kaplan-Meier survivorship analysis, log-rank test) are specifically designed to take into account censored data.

We found a slight decrease in pain for hips with labral reattachment compared to hips with labral resection at the 10-year followup (Table 4). At the 2-year followup and in the same patient series, also a small difference in the Merle d'Aubigné Postel score with a mean of 17 [range, 13-18] with labral reattachment versus 15 [range, 10-18] in labral resection ( $p=0.01$ ) was found [8]. In the literature, contradictory results have been reported comparing labral resection and reattachment in surgical treatment of FAI (Table 5). No difference in hip function was found for arthroscopic [5] or miniopen treatment [17, 18] at a mean followup of 3.8 and 4.5 years, respectively. Others have found decreased pain and improved function in arthroscopically treated hips with labral reattachment at an early mean followup ranging from 1.4 to 3.5 years (Table 5) [15, 16, 27, 29, 30, 33].

The survival rate of hips with labral reattachment was $78 \%$ (Fig. 2) with the endpoints for failure defined as conversion to THA, progression of osteoarthritis, and a clinical result with a Merle d'Aubigné-Postel score of $<15$ and increased compared to the $46 \%$ survival we observed in hips treated with labral resection (Fig. 3). This difference in survival can be attributed to the difference in the frequency of hips with a Merle d'Aubigne score of $<15$ (survival with this endpoint only was $83 \%$ and $48 \%$ at 10 years for labral reattachment and resection, respectively). Survival with progression of osteoarthritis or conversion to THA as the endpoints showed no difference at 10 years between hips with labral reattachment or resection. The difference in survival based on endpoint chosen is the result of the evolution of joint degeneration, which usually starts with increasing pain followed by progression of osteoarthritis and possibly conversion to THA. Therefore, some patients with conversion to THA or progression of osteoarthritis failed earlier as a result of a Merle d'Aubigné score decreasing under 15 points. Considering THA as a single endpoint (for reason of comparability), survival was $94 \%$ with labral reattachment and $87 \%$ with resection at 10 -year followup (Fig. 4). Comparing our results with noncomparative studies (and THA as the single endpoint), inferior midto long-term survival for hips with mainly labral resection compared with reattachment was found (Fig. 4; Table 5) $[1,3,4,6,13,16,18,21,23,24,27-29,31,34]$.

In conclusion, we found that in hips with osteochondroplasty of the neck and acetabular rim resection including labral reattachment for the treatment of mixedtype FAI, survival as we defined it was $78 \%$ compared with $46 \%$ in hips with labral resection (Fig. 1). However, survival defined as conversion to THA or progression of osteoarthritis alone showed no difference at 10 years. The difference in overall survival was the result of the difference in the frequency of hips with a Merle d'Aubigné score of $<15$. The main function of the labrum is to seal the joint and create a hydrostatic synovial fluid film to create a more homogenous load distribution, potentially increasing the durability of the joint $[10,25,30]$. This is the first study showing the clinical benefit of labral reattachment at a long-term followup in hips with open treatment for FAI. The current results suggest the importance of preserving the labrum and show that resection may put the hip at risk for early deterioration.

Acknowledgments Funding was provided by Schweizerischer Nationalfonds zur Förderung der Wissenschaftlichen Forschung (Grant Nos. PP00P3_144856 and P2BEP3_15067).

\section{References}

1. Beaulé PE, Le Duff MJ, Zaragoza E. Quality of life following femoral head-neck osteochondroplasty for femoroacetabular impingement. J Bone Joint Surg Am. 2007;89:773-779.

2. Beck M, Kalhor M, Leunig M, Ganz R. Hip morphology influences the pattern of damage to the acetabular cartilage: femoroacetabular impingement as a cause of early osteoarthritis of the hip. J Bone Joint Surg Br. 2005;87:1012-1018.

3. Beck M, Leunig M, Parvizi J, Boutier V, Wyss D, Ganz R. Anterior femoroacetabular impingement: part II. Midterm results of surgical treatment. Clin Orthop Relat Res. 2004;418:67-73.

4. Byrd JW, Jones KS. Arthroscopic management of femoroacetabular impingement: minimum 2-year follow-up. Arthroscopy. 2011;27:1379-1388.

5. Cetinkaya S, Toker B, Ozden VE, Dikmen G, Taser O. Arthroscopic labral repair versus labral debridement in patients with femoroacetabular impingement: a minimum 2.5 year follow-up study. Hip Int. 2016;26:20-24.

6. Chiron P, Espié A, Reina N, Cavaignac E, Molinier F, Laffosse JM. Surgery for femoroacetabular impingement using a minimally invasive anterolateral approach: analysis of 118 cases at 2.2-year follow-up. Orthop Traumatol Surg Res. 2012;98:30-38.

7. D'Aubigne RM, Postel M. Functional results of hip arthroplasty with acrylic prosthesis. J Bone Joint Surg Am. 1954;36:451-475. 
8. Espinosa N, Rothenfluh DA, Beck M, Ganz R, Leunig M. Treatment of femoro-acetabular impingement: preliminary results of labral refixation. J Bone Joint Surg Am. 2006;88:925-935.

9. Ferguson SJ, Bryant JT, Ganz R, Ito K. The influence of the acetabular labrum on hip joint cartilage consolidation: a poroelastic finite element model. J Biomech. 2000;33:953-960.

10. Ferguson SJ, Bryant JT, Ganz R, Ito K. An in vitro investigation of the acetabular labral seal in hip joint mechanics. $J$ Biomech. 2003;36:171-178.

11. Ganz R, Gill TJ, Gautier E, Ganz K, Krügel N, Berlemann U. Surgical dislocation of the adult hip a technique with full access to the femoral head and acetabulum without the risk of avascular necrosis. J Bone Joint Surg Br. 2001;83:1119-1124.

12. Holm I, Bolstad B, Lütken T, Ervik A, Røkkum M, Steen H. Reliability of goniometric measurements and visual estimates of hip ROM in patients with osteoarthrosis. Physiother Res Int. 2000;5:241-248.

13. Hufeland M, Krüger D, Haas NP, Perka C, Schröder JH. Arthroscopic treatment of femoroacetabular impingement shows persistent clinical improvement in the mid-term. Arch Orthop Trauma Surg. 2016;136:687-691.

14. Kaplan E, Meier P. Nonparametric estimation from incomplete observations. J Am Stat Assoc. 1958;53:457-481.

15. Larson CM, Giveans MR. Arthroscopic débridement versus refixation of the acetabular labrum associated with femoroacetabular impingement. Arthroscopy. 2009;25:369-376.

16. Larson CM, Giveans MR, Stone RM. Arthroscopic débridement versus refixation of the acetabular labrum associated with femoroacetabular impingement: mean 3.5-year follow-up. Am J Sports Med. 2012;40:1015-1021.

17. Laude F, Sariali E. [Treatment of FAI via a minimally invasive ventral approach with arthroscopic assistance. Technique and midterm results] [in German]. Orthopade. 2009;38:419-428.

18. Laude F, Sariali E, Nogier A. Femoroacetabular impingement treatment using arthroscopy and anterior approach. Clin Orthop Relat Res. 2009;467:747-752.

19. Martin RL, Sekiya JK. The interrater reliability of 4 clinical tests used to assess individuals with musculoskeletal hip pain. $J$ Orthop Sports Phys Ther. 2008;38:71-77.

20. McWhirk LB, Glanzman AM. Within-session inter-rater realiability of goniometric measures in patients with spastic cerebral palsy. Pediatr Phys Ther. 2006;18:262-265.

21. Murphy S, Tannast M, Kim YJ, Buly R, Millis MB. Débridement of the adult hip for femoroacetabular impingement: indications and preliminary clinical results. Clin Orthop Relat Res. 2004;429:178-181.

22. Murphy SB, Ganz R, Müller ME. The prognosis in untreated dysplasia of the hip. A study of radiographic factors that predict the outcome. J Bone Joint Surg Am. 1995;77:985-989.

23. Naal FD, Miozzari HH, Schär M, Hesper T, Nötzli HP. Midterm results of surgical hip dislocation for the treatment of femoroacetabular impingement. Am J Sports Med. 2012;40:1501-1510.

24. Naal FD, Miozzari HH, Wyss TF, Nötzli HP. Surgical hip dislocation for the treatment of femoroacetabular impingement in high-level athletes. Am J Sports Med. 2011;39:544-550.

25. Nepple JJ, Philippon MJ, Campbell KJ, Dornan GJ, Jansson KS, LaPrade RF, Wijdicks CA. The hip fluid seal-Part II: The effect of an acetabular labral tear, repair, resection, and reconstruction on hip stability to distraction. Knee Surg Sports Traumatol Arthrosc. 2014;22:730-736.

26. Nötzli HP, Wyss TF, Stoecklin CH, Schmid MR, Treiber K, Hodler J. The contour of the femoral head-neck junction as a predictor for the risk of anterior impingement. J Bone Joint Surg Br. 2002;84:556-560.

27. Palmer DH, Ganesh V, Comfort T, Tatman P. Midterm outcomes in patients with cam femoroacetabular impingement treated arthroscopically. Arthroscopy. 2012;28:1671-1681.

28. Peters CL, Schabel K, Anderson L, Erickson J. Open treatment of femoroacetabular impingement is associated with clinical improvement and low complication rate at short-term followup. Clin Orthop Relat Res. 2010;468:504-510.

29. Philippon MJ, Briggs KK, Yen YM, Kuppersmith DA. Outcomes following hip arthroscopy for femoroacetabular impingement with associated chondrolabral dysfunction: minimum two-year follow-up. J Bone Joint Surg Br. 2009;91:16-23.

30. Philippon MJ, Nepple JJ, Campbell KJ, Dornan GJ, Jansson KS, LaPrade RF, Wijdicks CA. The hip fluid seal-Part I: the effect of an acetabular labral tear, repair, resection, and reconstruction on hip fluid pressurization. Knee Surg Sports Traumatol Arthrosc. 2014;22:722-729.

31. Polesello GC, Lima FR, Guimaraes RP, Ricioli W, Queiroz MC. Arthroscopic treatment of femoroacetabular impingement: minimum five-year follow-up. Hip Int. 2014;24:381-386.

32. Reynolds D, Lucas J, Klaue K. Retroversion of the acetabulum. A cause of hip pain. J Bone Joint Surg Br. 1999;81:281-288.

33. Schilders E, Dimitrakopoulou A, Bismil Q, Marchant P, Cooke C. Arthroscopic treatment of labral tears in femoroacetabular impingement: a comparative study of refixation and resection with a minimum two-year follow-up. J Bone Joint Surg Br. 2011;93:1027-1032.

34. Steppacher SD, Anwander H, Zurmühle CA, Tannast M, Siebenrock KA. Eighty percent of patients with surgical hip dislocation for femoroacetabular impingement have a good clinical result without osteoarthritis progression at 10 years. Clin Orthop Relat Res. 2015;473:1333-1341.

35. Steppacher SD, Huemmer C, Schwab JM, Tannast M, Siebenrock KA. Surgical hip dislocation for treatment of femoroacetabular impingement: factors predicting 5-year survivorship. Clin Orthop Relat Res. 2014;472:337-348.

36. Tannast M, Hanke MS, Zheng G, Steppacher SD, Siebenrock KA. What are the radiographic reference values for acetabular underand overcoverage? Clin Orthop Relat Res. 2015;473:1234-1246.

37. Tannast M, Siebenrock KA, Anderson SE. Femoroacetabular impingement: radiographic diagnosis-what the radiologist should know. AJR Am J Roentgenol. 2007;188:1540-1552.

38. Tönnis D. General radiography of the hip joint. In: Tönnis D, ed. Congenital Dysplasia and Dislocation of the Hip. Heidelberg, Germany: Springer Verlag; 1987:100-142.

39. Wiberg G. The anatomy and roentgenographic appearance of a normal hip joint. Acta Chir Scand. 1939;83:7-38.

40. Wyss TF, Clark JM, Weishaupt D, Nötzli HP. Correlation between internal rotation and bony anatomy in the hip. Clin Orthop Relat Res. 2007;460:152-158. 